\title{
ESTUDO BIOQUÍMICO E SENSORIAL DO QUEIJO DE COALHO PRODUZIDO COM LEITE CRU E PASTEURIZADO NO ESTADO DO CEARÁ
}

\author{
SELENE DAIHA BENEVIDES * \\ FRANCISCO JOSÉ SIQUEIRA TELLES ** \\ ANTÔNIO CLÁUDIO LIMA GUIMARÃES ** \\ MARIA DO CARMO PASSOS RODRIGUES * *
}

\begin{abstract}
Procedeu-se estudo bioquímico e sensorial de queijos de coalho, elaborados a partir de leite cru (QLC) e leite pasteurizado/inoculado com Streptococcus thermophilus e Lactobacillus bulgaricus (QLP), mantidos sob temperatura ambiente (TA) e temperatura de refrigeração (TR). A maturação dos queijos foi avaliada mediante análise eletroforética das frações da caseína, utilizando-se gel de poliacrilamida na presença de sódio-dodecil-sulfato (SDS-PAGE). Também foram determinados o teor de tirosina e o índice de maturação. O método SDS-PAGE não apresentou resultados diferenciais entre os mesmos tipos de queijos sob diferentes temperaturas no período estudado, já os teores de tirosina elevaram-se durante o mesmo período. O índice de maturação evidenciou que o QLP foi o tipo de queijo que mais maturou. Os resultados da análise sensorial mostraram que não houve diferença significativa ao nível de 5\% entre o QLC-TR e QLP-TR aos 4, 30 e 60 dias. Verificou-se certa preferência dos provadores pelo QLC-TR aos 4 e 60 dias.
\end{abstract}

\section{INTRODUÇÃO}

Segundo GREEN et al. (1984), uma das mais importantes considerações na elaboração do queijo é a obtenção de produto aceitável sob os pontos de vista de sabor e textura. A textura é a manifestação das características reológicas e depende da composição e estrutura do queijo. A textura do queijo pode ser influenciada pelas condições de várias etapas durante seu

*ngenheira de Alimentos, M.Sc., Universidade Federal do Ceará (UFC).

(e-mail: sdb@fortalnet.com.br).

** Professor Adjunto IV, Universidade Federal do Ceará (UFC). 
processamento. A formação e manuseio da coalhada afeta sua habilidade de reter gordura e umidade, influenciando assim sua composição e conseqüentemente sua textura.

A proteólise pode ocorrer no leite, na sua coagulação induzida enzimaticamente e na maturação do queijo. A proteólise tem sido apontada como responsável pelo desenvolvimento do sabor e da textura da maioria dos tipos de queijos (LAW, 1987 e FOX, 1989). O desenvolvimento do sabor de queijos está ligado ao fracionamento da proteína em peptídios e aminoácidos livres (SCHORMULLER, 1968). O fracionamento da proteína tem sido usado como índice da maturação do queijo, normalmente medido pela quantidade de peptídios e aminoácidos solúveis em filtrados ácidos preparados do queijo. Os métodos mais freqüentemente usados são baseados na determinação das concentrações de tirosina e triptofano em filtrados de ácido tricloroacético (TCA) (SAMPLES et al., 1984).

O objetivo deste trabalho foi estudar as características do queijo de coalho, elaborado a partir de leite cru e pasteurizado/inoculado com fermento láctico selecionado, maturado sob diferentes temperaturas. $O$ queijo foi avaliado quanto aos aspectos bioquímicos e sensoriais, identificando-se as alterações proteolíticas que ocorrem no processo de maturação.

\section{MATERIAL E MÉTODOS}

\subsection{MATERIAL}

Foram analisadas 100 (cem) amostras de queijo tipo coalho, pesando cerca de $250 \mathrm{~g}$ cada uma. Cinquenta (50) amostras foram produzidas com leite bovino cru e sem inoculação de cultura láctica e 50 com leite bovino pasteurizado/inoculado com cultura láctica da Chr. Hansen, composta de Lactobacillus bulgaricus e Streptococcus thermophilus (YC-180 - DVS Chr. Hansen). As amostras foram mantidas sob temperatura ambiente $\left(29^{\circ} \mathrm{C}\right)$ e de refrigeração $\left(10^{\circ} \mathrm{C}\right)$. Cada tratamento foi realizado com 5 (cinco) repetições cada.

\subsection{MÉTODOS}

As amostras foram extraídas do centro de cada bloco de queijo, trituradas, acondicionadas em potes de polietileno e conservadas em congelador até a realização das análises. As determinações bioquímicas foram realizadas nas amostras recém trituradas e aos $4,7,30,60$ e 90 dias. A análise sensorial ocorreu aos 4, 30 e 60 dias (somente para os queijos refrigerados devido a perda de umidade dos mesmos em temperatura ambiente ter sido elevada, resultando em amostras com desidratação intensa). 


\subsubsection{Atividade Proteolítica}

\subsubsection{1 Índice de Maturação (IM)}

Obteve-se o índice de maturação pela relação percentual entre os teores de proteína solúvel (extração pelo método KOSIKOWSKI (1982) e determinação do nitrogênio pelo método de KJELDAHL) e proteína total (LANARA, 1981).

\subsubsection{Teor de Tirosina}

Os aminoácidos solúveis em ácido tricloroacético (TCA) foram avaliados pelo método de LOWRY et al. (1951) e expressos em termos de concentração de tirosina.

\subsubsection{SDS-PAGE}

Aproximadamente $0,01 \mathrm{~g}$ de amostra de queijo desengordurada foi solubilizada em $2 \mathrm{~mL}$ de solução tampão e alíquotas de $6 \mu \mathrm{L}$ foram submetidas a Sodium Dodecyl Sulfate - Polyacrylamide Gel Electroforesis (SDS-PAGE) (LAEMMLI, 1970). Utilizou-se gel com 15\% de acrilamida e $1,5 \mathrm{~mm}$ de espessura para monitorar a proteólise da caseína durante a maturação do queijo.

Os padrões das frações de caseínas utilizados foram os seguintes: $\alpha_{\mathrm{s}}$ caseína (C-6780), $\beta$ - caseína (C-6905) e $\kappa$ - caseína (C-0406), obtidas da Sigma Chemical (USA). Os géis foram submetidos a leitura em densitômetro computadorizado modelo CGA - Supercello 5 (Italy).

\subsubsection{Análise Sensorial}

Realizou-se análise sensorial mediante teste de aceitação, com 31 provadores não treinados (para 4 e 30 dias) e 20 provadores não treinados (para 4 e 60 dias), utilizando escala hedônica mista (MORAES, 1988 e SMITH, 1985).

As amostras foram padronizadas em forma de cubos de aproximadamente $2 \mathrm{~cm}^{3}$, codificadas com números aleatórios de três dígitos, servidas em temperatura ambiente, uma de cada vez e de forma casualisada aos provadores, em duas sessões.

\subsubsection{Análise Estatística}

Avaliou-se o resultado mediante análise de variância, com medidas repetidas ao longo do tempo. As comparações múltiplas entre os queijos foram efetuadas e confirmadas pelo Teste de Tuckey e entre os dias de maturação pelo Teste de Hipóteses. 
Na hipótese da variável não satisfazer as condições de normalidade usouse transformação logarítmica dos dados da variável. O resultado da análise sensorial foi avaliado pelos testes de Mann-Whitney e de Wilcoxon.

\section{RESULTADOS E DISCUSSÃO}

\subsection{ATIVIDADE PROTEOLÍTICA}

Os queijos produzidos a partir de leite cru e os de leite pasteurizado/inoculado com Streptococcus thermophilus e Lactobacillus bulgaricus foram denominados de QLC e QLP, respectivamente, sendo que TA e TR representam temperatura ambiente e temperatura de refrigeração.

\subsection{1 Índice de maturação}

A análise estatística (Tabela 1 ) revelou que não houve diferença significativa $(p>0,05)$ para o QLC-TA com 7, 30 e 60 dias de maturação e para o QLP-TA com 60 e 90 dias, entretanto o QLC-TR e o QLP-TR diferiram $(p \leq 0,05)$ em todos os dias de cura. Aos 30 dias, o QLP-TA, QLPTR e QLC-TR apresentaram os maiores valores, resultado semelhante ao obtido por REITER et al. (1969). Estes autores, estudando a proteólise em queijo, afirmaram que a maior hidrólise da proteína para nitrogênio solúvel ocorreu no primeiro mês e continuou em menor grau até $03^{\circ}$ mês de maturação.

Todos os queijos apresentaram valores crescentes durante a maturação, sendo que o QLC-TA revelou menor variação (Figura 1). Os queijos inoculados com fermento e maturados em temperatura ambiente apresentaram valores superiores aos dos queijos sem fermento sob a mesma temperatura, resultado que está de acordo com LIMA et al. (1998) (Tabela 1).

\subsubsection{Teor de tirosina}

Os valores médios de tirosina evidenciaram que, QLC-TA diferiu estatisticamente $(p \leq 0,05)$ aos $4,7,30$ e 60 dias de maturação, não apresentando diferença $(p>0,05)$ aos 90 dias em relação aos 30 e 60 dias. O QLC-TR somente não apresentou diferença $(p>0,05)$ nos tempos de 60 e 90 dias. QLP-TA não diferiu $(p>0,05)$ de 4 para 7 e 30 dias e de 60 para 90 dias. QLP-TR diferiu $(p \leq 0,05)$ em todos os períodos de maturação (Tabela 1). 


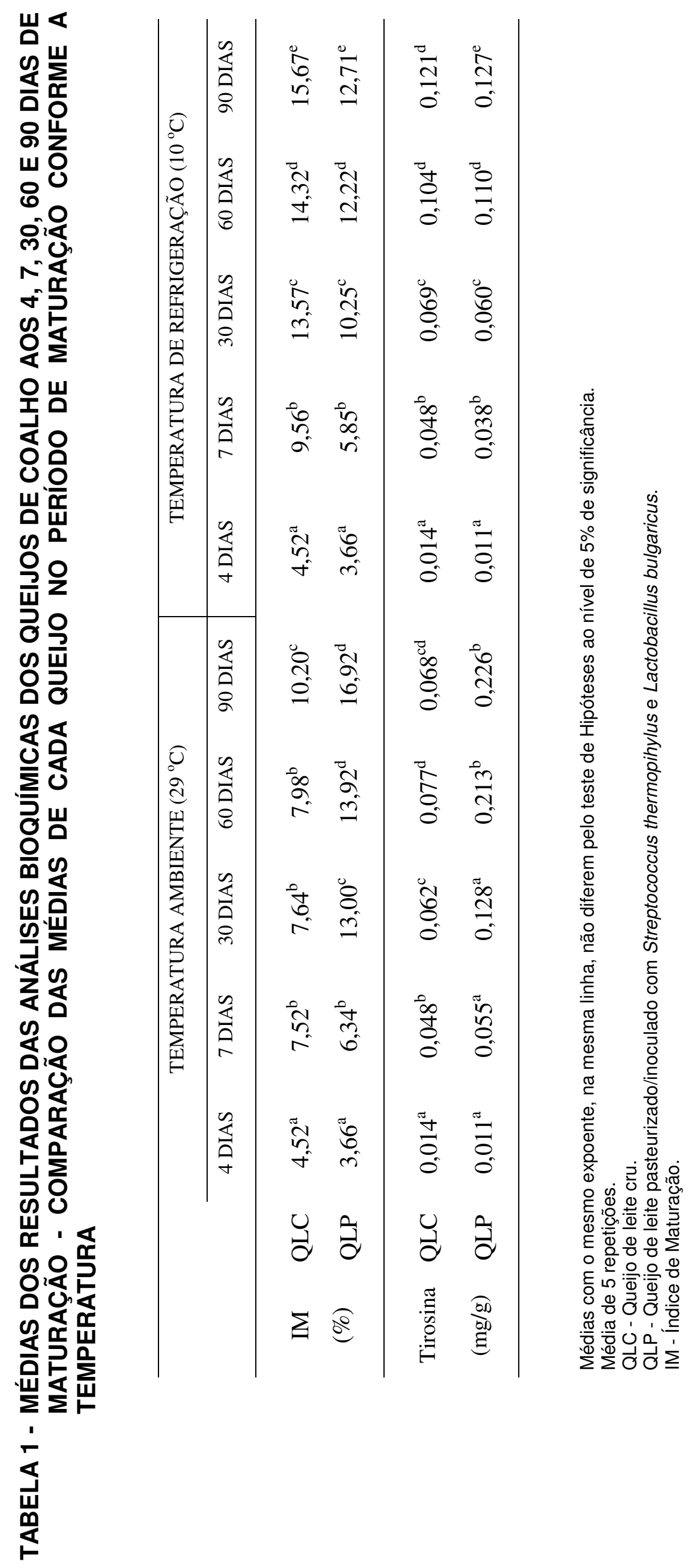

B.CEPPA, Curitiba, v. 18, n. 2, jul./dez.2000 


\section{FIGURA 1 - ÍNDICE DE MATURACÃO DOS QUEIJOS DE COALHO PRODUZIDOS COM LEITE CRU (QLC) E PASTEURIZADO/ INOCULADO (QLP)}

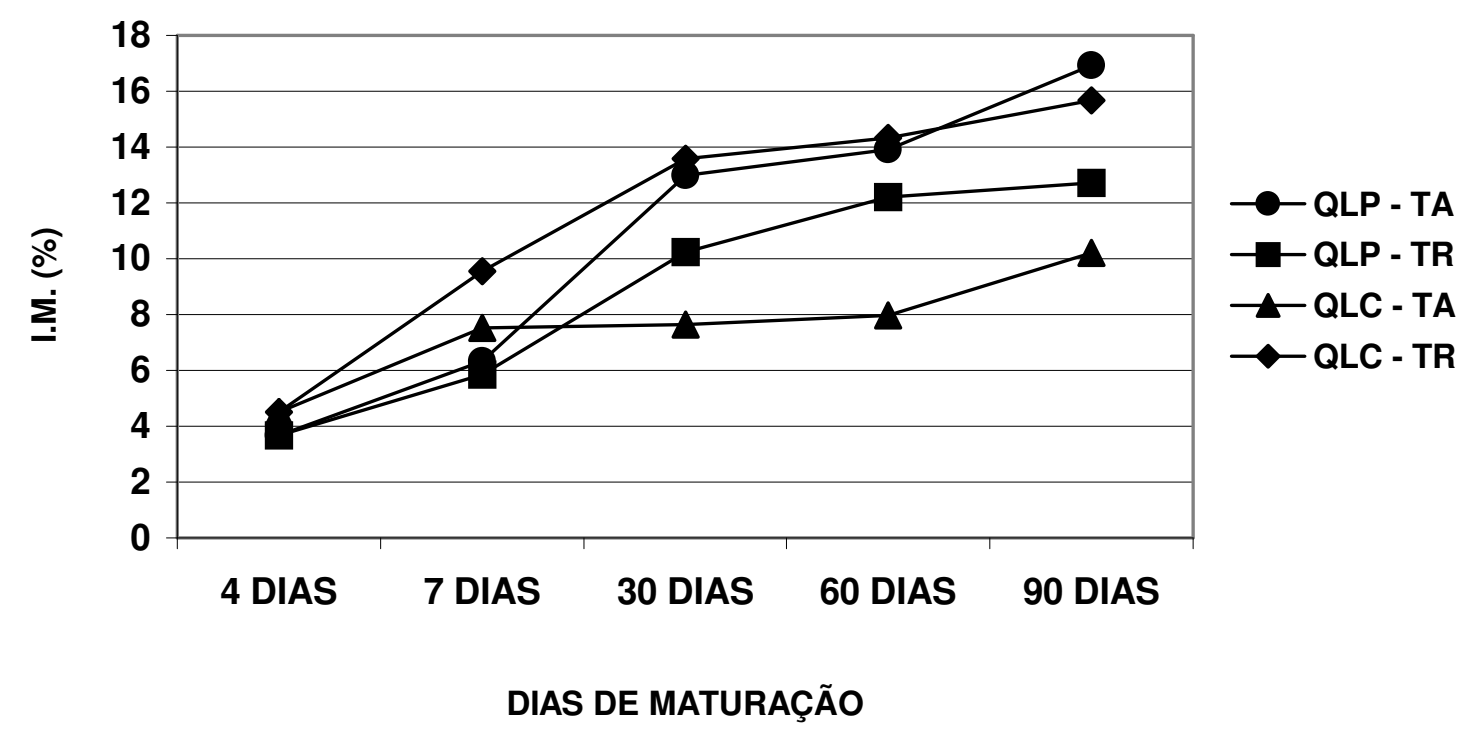

Os teores de tirosina mostraram (Figura 2) tendência crescente no decorrer do período de maturação. O QLP apresentou maior índice de tirosina, devido provavelmente, ao fermento lático selecionado.

Os resultados encontrados estão de acordo com VAKALERIS \& PRICE (1959), quando afirmam que a tirosina solúvel tende a aumentar mais rapidamente nos primeiros estágios de maturação e que existe boa correlação entre o teor de tirosina e o índice de maturação dos queijos (Figura 2).

AUGUSTO et al. (1998) trabalhando com a avaliação de métodos para quantificação da proteólise em queijo Prato, inoculado com Lactococcus lactics ssp lactis, durante intervalos de $1,15,30$ e 45 dias de cura, mantidos a temperatura de $5{ }^{\circ} \mathrm{C}$, encontraram valores crescentes de tirosina na avaliação da maturação.

\subsubsection{SDS-PAGE}

Os padrões da eletroforese em gel (SDS-PAGE) dos queijos de coalho, maturados durante $4,7,30,60$ e 90 dias com diferentes tratamentos são mostrados nas Figuras 3, 4, 5 e 6. 


\section{FIGURA 2 - TEOR DE TIROSINA DOS QUEIJOS DE COALHO PRODUZIDOS COM LEITE CRU (QLC) E PASTEURIZADO/ INOCULADO (QLP)}

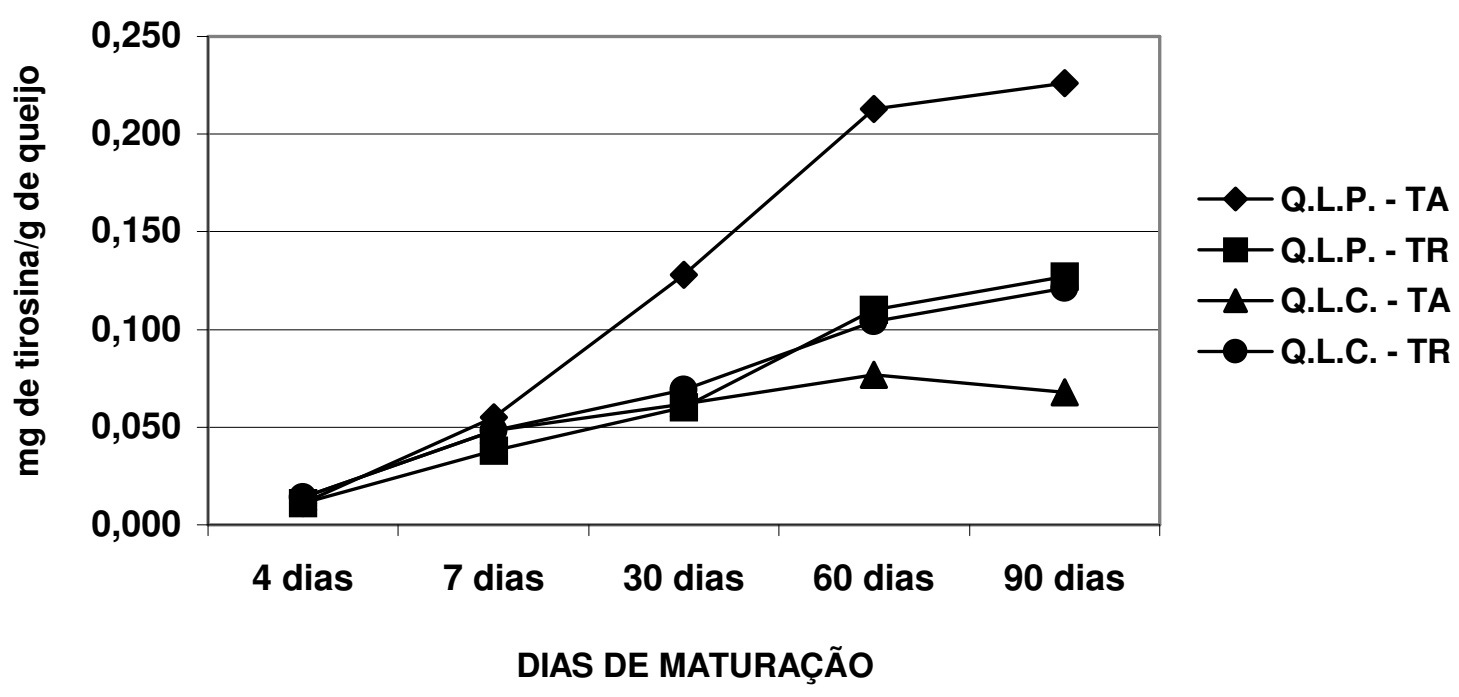

As principais proteínas presentes no queijo são a $\alpha_{s 1}, \alpha_{s 2}, \beta$ e para- $\kappa$-cas (FARKYE \& FOX, 1992). Modificação na fração $\alpha$ e $\beta$-cas foi observada nos géis do QLC-TR, QLP-TA e QLP-TR aos 30, 60 e 90 dias, quando comparados aos 4 e 7 dias.

Segundo BASCH et al. (1989) em queijos maturados pode ocorrer clivagem da $\beta$-caseína levando à formação de $\gamma_{1}, \gamma_{2}$ e $\gamma_{3}$ caseína. No entanto, a $\alpha_{\mathrm{s} 2}$-cas e a para- $\kappa$-cas resistem a períodos acima de 70 semanas antes de se degradarem. No presente estudo, até 12 semanas, nenhuma alteração foi observada.

O QLC, tanto na temperatura ambiente como na de refrigeração, mostrou uma banda no $4^{\circ}$ dia entre as frações $\beta$-cas e provavelmente para- $\kappa$-cas, a qual não é revelada nos períodos posteriores da maturação (Figuras 3 e 4).

A suposta fração para-א-caseína não parece ser produto da maturação, mas sim do próprio queijo, uma vez que apresenta comportamento constante em todos os géis para os diferentes tipos de tratamentos.

BASCH et al. (1989), GREEN \& FOSTER (1974) e NATH \& LEDFORD (1973) depois de estudarem a proteólise primária, durante a maturação de queijos, afirmaram que a para-א-caseína, ao contrário de outras proteínas e peptídios, não foi degradada durante a maturação. 


\begin{abstract}
FIGURA 3 - SDS-PAGE DE PROTEÍNAS EXTRAÍDAS DO QUEIJO DE COALHO PRODUZIDO COM LEITE CRU E MATURADO SOB TEMPERATURA AMBIENTE $\left(29^{\circ} \mathrm{C}\right)$ DURANTE 4,7 , 30, 60 E 90 DIAS
\end{abstract}

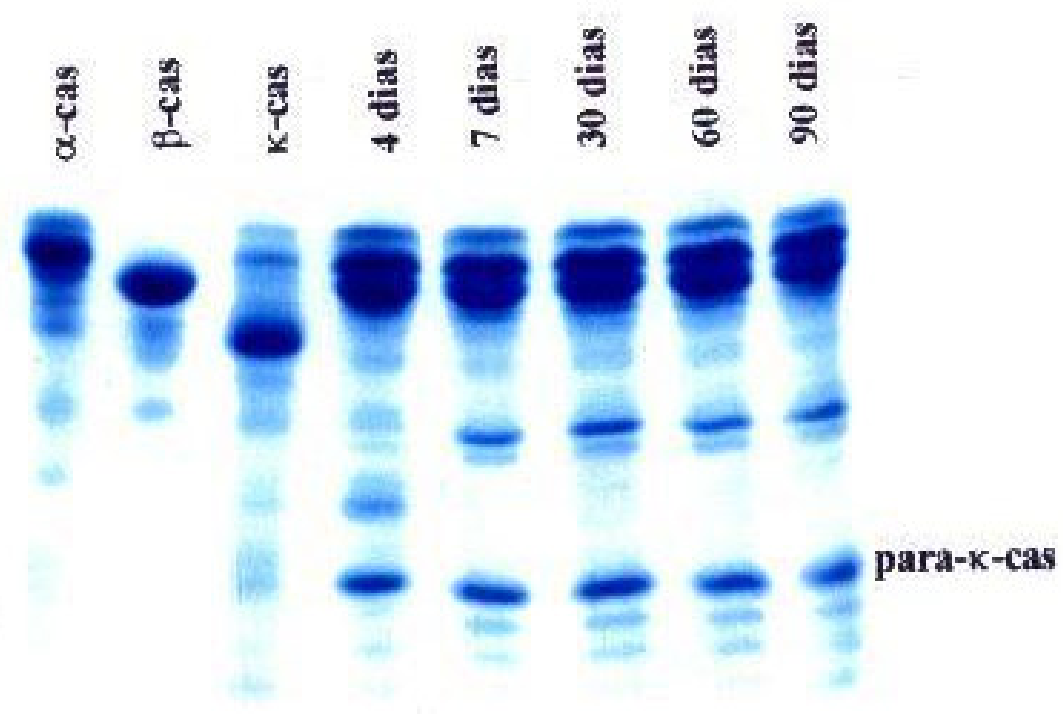

FIGURA 4 - SDS-PAGE DE PROTEÍNAS EXTRAÍDAS DO QUEIJO DE COALHO PRODUZIDO COM LEITE CRU E MATURADO SOB TEMPERATURA DE REFRIGERAÇÃO (10 $\left.{ }^{\circ} \mathrm{C}\right)$ DURANTE 4, 7, 30, 60 E 90 DIAS

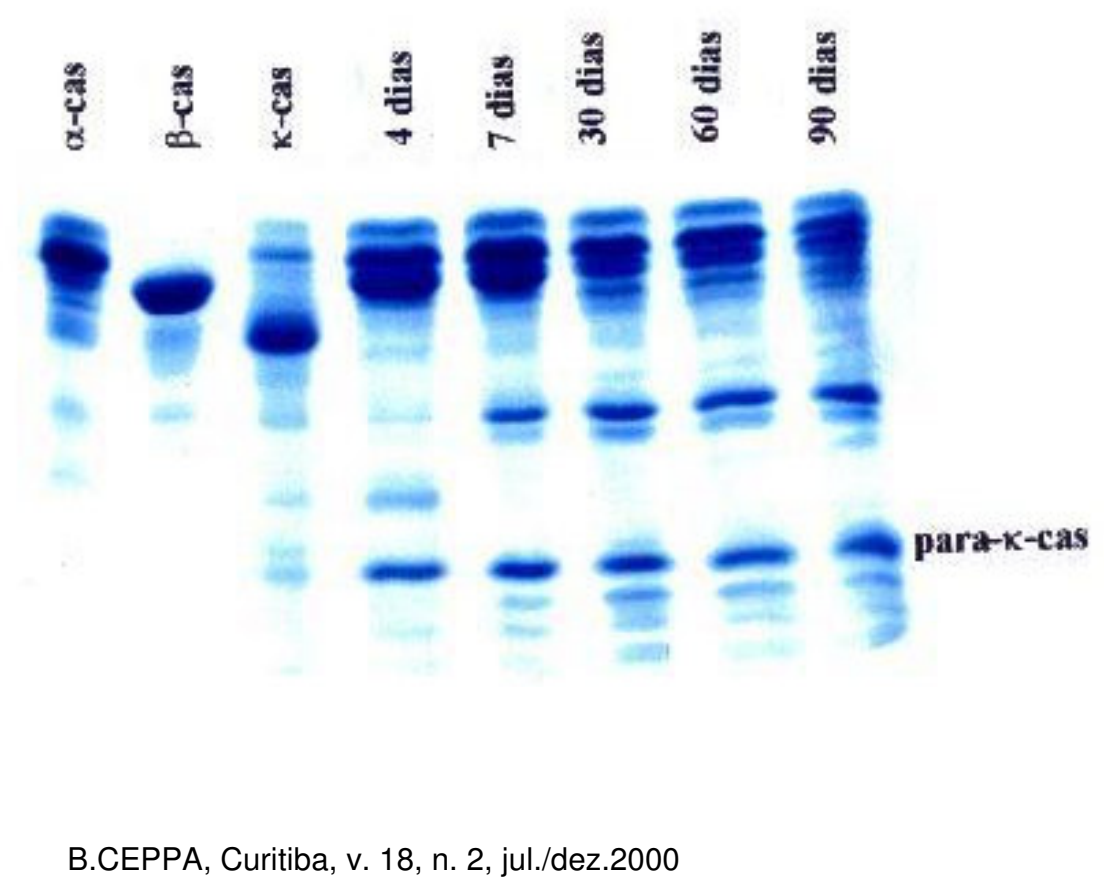


Os queijos QLP-TA e QLP-TR (Figuras 5 e 6) apresentaram número maior de bandas que o QLC-TA e QLC-TR (Figuras 3 e 4), entre $\circ 7^{\circ}, 30^{\circ}, 60^{\circ}$ e $90^{\circ}$ dia. Tal fato pode resultar da clivagem e interação das proteínas induzidas termicamente ou dos próprios microorganismos presentes na cultura lática. Estudos mais detalhados merecem ser realizados quanto ao uso do gel (SDS-PAGE) na detecção da proteólise do queijo de coalho. Entretanto, tais resultados assemelham-se aos obtidos por BASCH et al. (1989) quanto ao número de bandas e sua intensidade nas regiões entre $\beta$ -

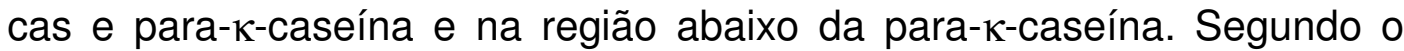
referido autor ocorre quebra das principais frações durante a maturação do queijo, isto é, a $\beta$-caseína em $\gamma_{2}$ e $\gamma_{3}$-cas e $\alpha_{s 2}$ e $\alpha_{s 1-c a s}$ em grandes peptídios.

\subsection{ANÁLISE SENSORIAL}

O estudo estatístico da análise sensorial dos queijos refrigerados encontram-se nas Tabelas 2, 3 e 4. Observa-se pela Tabela 2 que houve diferença significativa $(p=0,000)$ nas médias atribuídas pelos provadores no tempo de quatro e trinta dias para os queijos de leite cru e leite pasteurizado, sendo que a média atribuída ao queijo no tempo de quatro dias apresentou-se superior a de 30 dias para ambos os tipos de queijos (Figura 7).

\section{TABELA 2 - TESTE DO SINAL DE WILCOXON PARA COMPARAÇÃO DAS NOTAS OBTIDAS NO TEMPO DE QUATRO E TRINTA DIAS PARA O QUEIJO DE LEITE CRU E LEITE PASTEURIZADO SOB TEMPERATURA DE REFRIGERAÇÃO}

\begin{tabular}{l|c|c|c|c|c}
\hline \multirow{2}{*}{ Hipótese } & $\begin{array}{c}\text { Condição } \\
\text { observada (nota) }\end{array}$ & $\begin{array}{c}\text { Número de } \\
\text { observações }\end{array}$ & $\begin{array}{c}\text { Posto } \\
\text { médio }\end{array}$ & $\mathrm{Z}$ & $\mathrm{p}$ \\
\hline \multirow{2yyyyy}{*}{$\begin{array}{l}\text { nota 30 dias } \\
\text { nota 4 dias } \\
\text { queijo de leite } \\
\text { cru }\end{array}$} & 30 dias < 4 dias & 24 & 14,77 & & \\
\cline { 2 - 6 } & 30 dias $>4$ dias & 3 & 7,83 & $-3,993$ & 0,000 \\
\cline { 2 - 6 } & 30 dias $=4$ dias & 4 & & & \\
\hline \multirow{2}{*}{$\begin{array}{l}\text { nota 30 dias }= \\
\text { nota 4 dias } \\
\text { queijo de leite } \\
\text { pasteurizado }\end{array}$} & 30 dias $<4$ dias & 24 & 15,98 & & \\
\cline { 2 - 6 } & 30 dias $>4$ dias & 5 & 10,3 & $-3,611$ & 0,000 \\
\cline { 2 - 6 } & 30 dias $=4$ dias & 2 & & & \\
\hline
\end{tabular}

$\mathrm{Z}=$ normal

$\mathrm{p}=$ nível descritivo. 
FIGURA 5 - SDS-PAGE DE PROTEÍNAS EXTRAÍDAS DO QUEIJO DE COALHO PRODUZIDO COM LEITE PASTEURIZADO/ INOCULADO COM St. thermophylus E L. bulgaricus E MATURADO SOB TEMPERATURA AMBIENTE $\left(29^{\circ} \mathrm{C}\right)$ DURANTE 4, 7, 30, 60 E 90 DIAS

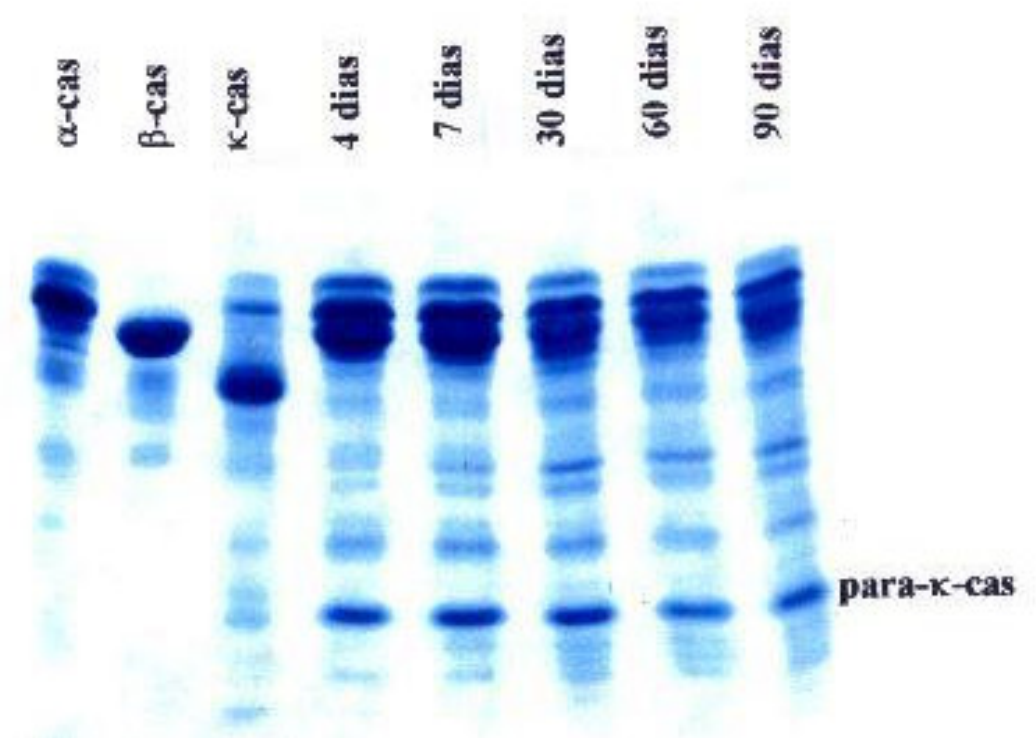

FIGURA 6 - SDS-PAGE DE PROTEÍNAS EXTRAÍDAS DO QUEIJO DE COALHO PRODUZIDO COM LEITE PASTEURIZADO/ INOCULADO COM St. thermophylus E L. bulgaricus E MATURADO SOB TEMPERATURA DE REFRIGERAÇÃO $\left(10^{\circ} \mathrm{C}\right)$ DURANTE $4,7,30,60 \mathrm{E} 90$ DIAS

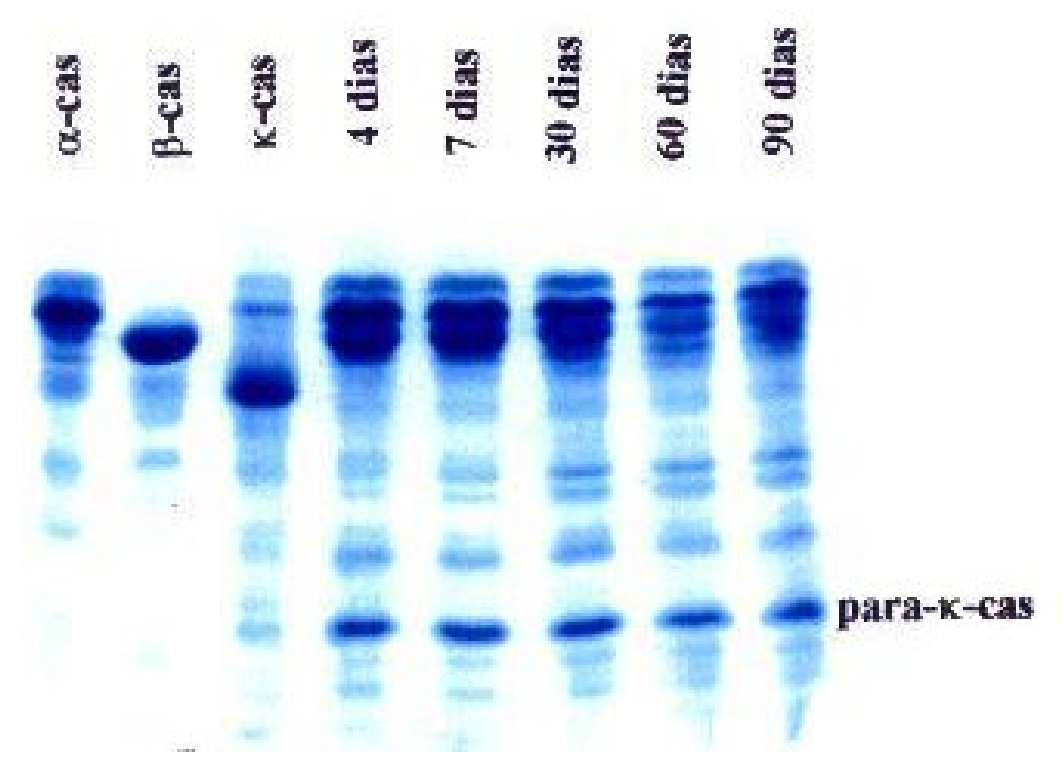


FIGURA 7 - MÉDIA DAS NOTAS ATRIBUÍDAS PELOS PROVADORES PARA O QUEIJO DE LEITE CRU E PASTEURIZADO EM FUNÇÃO DO TEMPO DE QUATRO E TRINTA DIAS DE MATURAÇÃO SOB TEMPERATURA REFRIGERADA $\left(10^{\circ} \mathrm{C}\right)$

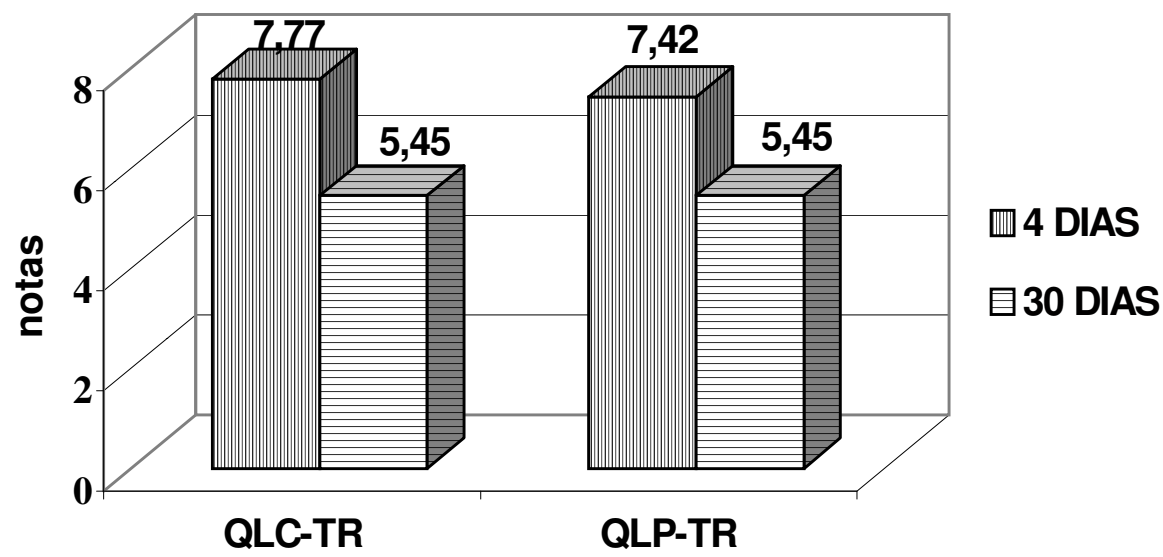

No tempo de 4 e 60 dias (Tabela 3), para o queijo de leite cru não houve diferença significativa ( $p=0,167)$, ao contrário do queijo de leite pasteurizado ( $p=0,021$ ), entretanto nos dois casos o queijo com quatro dias obteve maior nota dos provadores (Figura 8).

TABELA 3 - TESTE DO SINAL DE WILCOXON PARA COMPARAÇÃO DAS NOTAS OBTIDAS NO TEMPO DE QUATRO E SESSENTA DIAS PARA O QUEIJO DE LEITE CRU E LEITE PASTEURIZADO SOB TEMPERATURA DE REFRIGERAÇÃO

\begin{tabular}{|c|c|c|c|c|c|}
\hline Hipótese & $\begin{array}{c}\text { Condição } \\
\text { observada (nota) }\end{array}$ & $\begin{array}{l}\text { Número de } \\
\text { observações }\end{array}$ & $\begin{array}{l}\text { Posto } \\
\text { médio }\end{array}$ & $\mathrm{Z}$ & $\mathrm{p}$ \\
\hline \multirow{4}{*}{$\begin{array}{l}\text { nota } 60 \text { dias }= \\
\text { nota } 4 \text { dias } \\
\text { queijo de } \\
\text { leite cru }\end{array}$} & 60 dias $<4$ dias & 11 & 8,59 & & \\
\hline & 60 dias $>4$ dias & 5 & 8,3 & $-1,382$ & 0,167 \\
\hline & 60 dias $=4$ dias & 4 & & & \\
\hline & Total & 20 & & & \\
\hline \multirow{4}{*}{$\begin{array}{l}\text { nota } 60 \text { dias }= \\
\text { nota } 4 \text { dias } \\
\text { queijo de } \\
\text { leite } \\
\text { pasteurizado }\end{array}$} & 60 dias $<4$ dias & 14 & 10,86 & & \\
\hline & 60 dias $>4$ dias & 5 & 7,6 & $-2,315$ & 0,021 \\
\hline & 60 dias $=4$ dias & 1 & & & \\
\hline & Total & 20 & & & \\
\hline
\end{tabular}

$\mathrm{Z}=$ normal.

$\mathrm{p}=$ nível descritivo. 


\section{FIGURA 8 - MÉDIA DAS NOTAS ATRIBUÍDAS PELOS PROVADORES PARA O QUEIJO DE LEITE CRU E PASTEURIZADO EM FUNÇÃO DO TEMPO DE QUATRO E SESSENTA DIAS DE MATURAÇÃO SOB TEMPERATURA REFRIGERADA $\left(10^{\circ} \mathrm{C}\right)$}

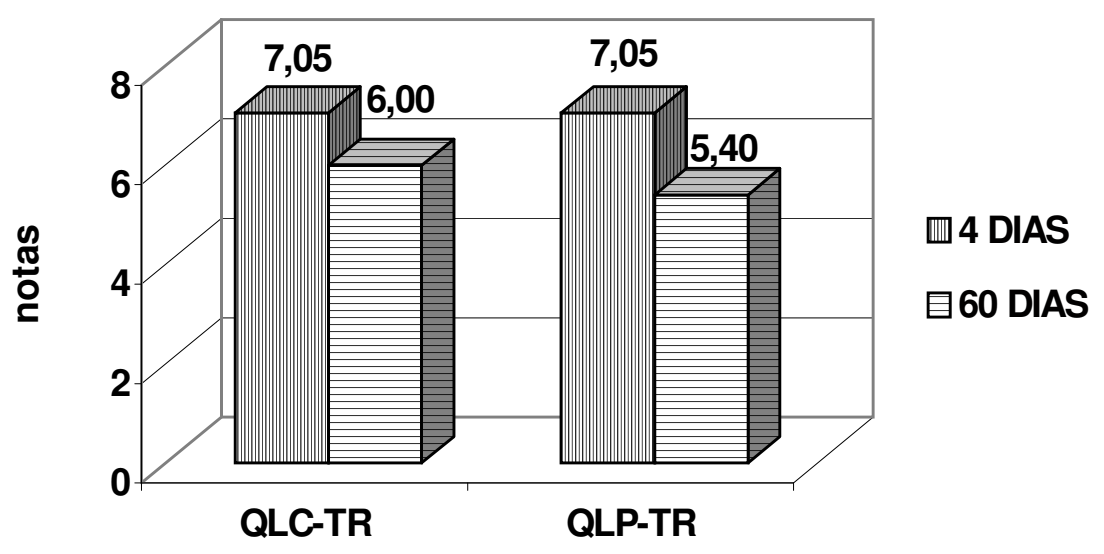

Comparando-se as notas obtidas para o queijo de leite cru e leite pasteurizado em função de cada dia de maturação, pelo teste de MannWhitney (Tabela 4), pode-se observar que não houve diferença significativa $(p=0,927)$ para quatro dias, trinta dias $(p=0,932)$ e para 60 dias $(p=0,304)$. Entretanto, observando a Figura 9 verifica-se que as notas atribuídas pelos provadores para o queijo de leite cru aos 60 dias foram maiores que as obtidas pelo queijo de leite pasteurizado.

TABELA 4 - TESTE DE MANN-WHITNEY PARA COMPARAÇÃO DAS NOTAS OBTIDAS PELOS TIPOS DE QUEIJO EM FUNÇÃO DOS DIAS DE MATURAÇÃO

\begin{tabular}{|c|c|c|c|c|c|}
\hline $\begin{array}{c}\text { Dias de } \\
\text { Maturação }\end{array}$ & Queijo & $\begin{array}{l}\text { Número de } \\
\text { observações }\end{array}$ & $\begin{array}{l}\text { Posto } \\
\text { médio }\end{array}$ & $\begin{array}{c}\text { Mann- } \\
\text { Whitney }\end{array}$ & $\mathrm{p}$ \\
\hline \multirow{3}{*}{ quatro } & Leite Cru & 51 & 51,25 & 1287,5 & 0,927 \\
\hline & Leite Pasteurizado & 51 & 51,75 & & \\
\hline & Total & 102 & & & \\
\hline \multirow{3}{*}{ trinta } & Leite Cru & 31 & 31,31 & 474,5 & 0,932 \\
\hline & Leite Pasteurizado & 31 & 31,69 & & \\
\hline & Total & 62 & & & \\
\hline \multirow{3}{*}{ sessenta } & Leite Cru & 20 & 22,38 & 162,5 & 0,304 \\
\hline & Leite Pasteurizado & 20 & 18,63 & & \\
\hline & Total & 40 & & & \\
\hline
\end{tabular}

$\mathrm{p}=$ nível descritivo. 


\section{FIGURA 9 - COMPARAC̄̃O DAS MÉDIAS DAS NOTAS ATRIBUÍDAS PELOS PROVADORES PARA CADA TIPO DE QUEIJO EM FUNÇÃO DE CADA DIA DE MATURAÇÃO SOB TEMPERATURA DE REFRIGERAÇÃO $\left(10^{\circ} \mathrm{C}\right)$}

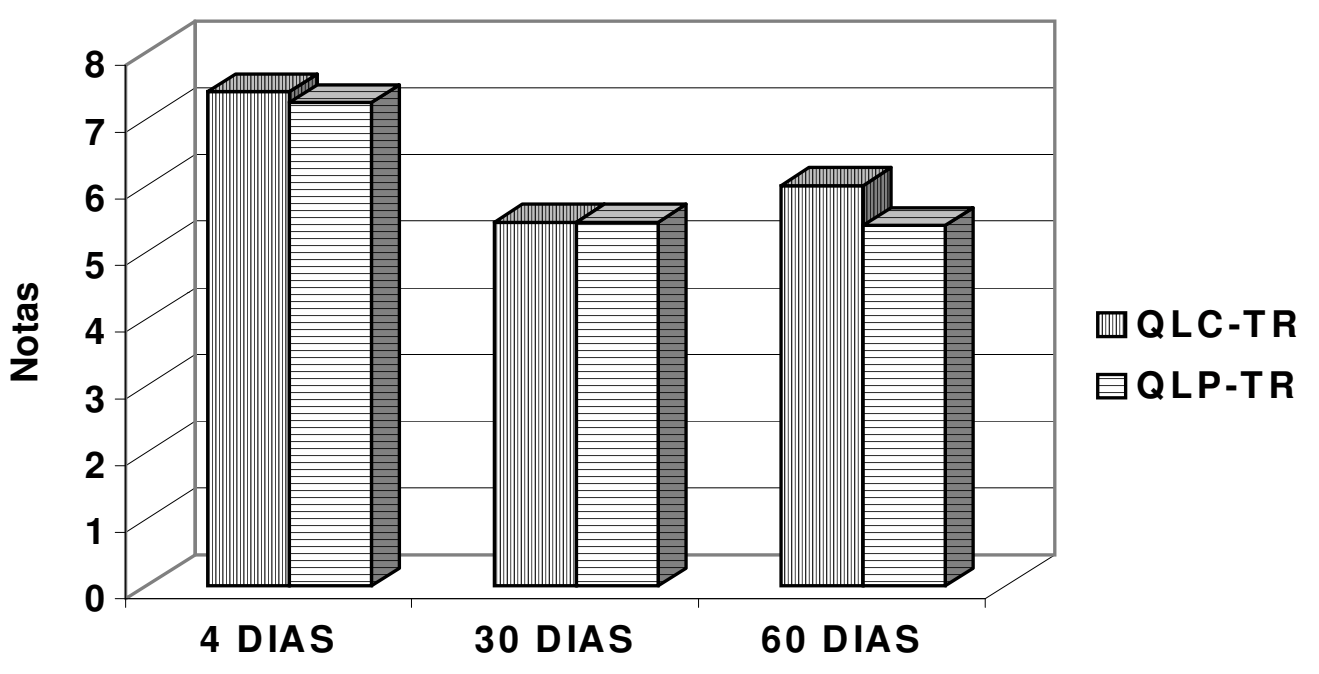

O sabor e a textura foram os termos sensoriais mais citados pelos provadores para os queijos de leite cru com 30 dias e 60 dias de maturação. Já para os queijos de leite pasteurizado com 30 e 60 dias, os termos mais citados foram textura e maciez, devido, provavelmente, à degradação das proteínas e ao teor de gordura do leite. Segundo SIQUEIRA et al. (1986) o teor de gordura do leite apresenta efeito marcante na qualidade do queijo em termos de textura, palatabilidade e firmeza.

O índice de maturação (Tabela 1) mostrou-se maior para o queijo de leite cru do que para o queijo de leite pasteurizado, refletindo maior proteólise e conseqüentemente melhor maciez e textura. Estas características, segundo GREEN \& MANNING (1982), são fatores que influenciam na determinação da aceitabilidade do queijo maturado.

\section{CONCLUSÃo}

O índice de maturação ou índice de extensão da proteólise apresentou maior valor para o QLP-TA, com 90 dias de maturação, seguido pelo QLCTR, QLP-TR e QLC-TA, devido em parte ao uso da cultura lática termofílica.

O teor de tirosina apresentou valores crescentes ao longo do período de maturação, podendo ser utilizado para correlacionar o índice de maturação 
dos queijos, com a vantagem de tratar-se de método rápido para avaliação da proteólise.

A eletroforese, usada em combinação com outros métodos, melhora o entendimento dos processos proteolíticos envolvidos na maturação de queijos.

$\mathrm{Na}$ avaliação sensorial observou-se preferência pelo QLC-TR aos quatro dias, devido provavelmente ao hábito de consumir queijo recém elaborado e aos sessenta dias como resposta às transformações bioquímicas que modificaram a estrutura do queijo durante a maturação.

A boa aceitação do QLC-TR e do QLP-TR aos 60 dias de maturação evidencia perspectiva para exploração deste novo tipo de queijo (queijo de coalho maturado), quer seja produzido com leite cru ou com leite pasteurizado. O queijo preferido pelos julgadores foi o QLC-TR aos 60 dias de maturação.

Sugere-se a realização de mais pesquisas sobre as características proteolíticas, lipolíticas, microbiológicas e reológicas do queijo de coalho maturado.

\section{Abstract}

Cheeses known as "queijo de coalho" made from raw milk (QLC) and pasteurized milk inoculated with Streptococcus thermophilus and Lactobacillus bulgaricus (QLP) were analyzed in the biochemical aspects during $4,7,30,60$ and 90 days of maturation at room temperature-TA $\left(29^{\circ} \mathrm{C}\right)$ and refrigerated temperature-TR $\left(10^{\circ} \mathrm{C}\right)$ and sensorial evaluation was carried out in the $30^{\text {th }}$ and $60^{\text {th }}$ day of maturation at TR. The maturation of the cheeses was evaluated through electrophoresis of the casein fractions by using poliacrylamida gel in the presence of sodium-dodecyl-sulfato (SDS-PAGE), tyrosine and maturation index. SDS-PAGE presented no difference among the same types of cheeses under different temperatures. The tyrosine index increased during the same period. The maturation index showed the highest value to QLP followed by QLC-TR, QLP-TR and QLC-TA. The results of the sensorial evaluation showed no significant difference at the level of $5 \%$ between QLC-TR and QLP-TR to the fourth, thirty and sixty days in spite of QLC-TR have presented a certain preference to the 4 and 60 days.

\section{REFERÊNCIAS}

1 AUGUSTO, M. M.; SILVA, A. T.; VIOTTO, W. H. et al. Avaliação de métodos para quantificação da proteólise em queijo tipo prato. Revista Indústria de Laticínios, p. 65-69, maio/jun. 1998.

2 BASCH, J. J.; FARRELL, H. M. JR.; WALSH, R. A. et al. Development of a quantitative model for enzyme-catalyzed, timedependent changes in protein composition of cheddar cheese during storage. Journal of Dairy Science, v. 72, p. 591-603, 1989. 
3 FARKYE, N. Y.; FOX, P. F. Contribution of plasmin to cheddar cheese ripening: effect of added plasmin. J. Dairy Res., v. 59, p. 209-216, 1992.

4 FOX, P. F. Proteolysis during cheese manufacture and ripening. J. Dairy Sci., v. 72, p. 1379-1400, 1989.

5 GREEN, M. L. DAVIS, F. L.; LAW, B. A. Advances in the microbiology and biochemistry of cheese and fermented milk. Londres: Elsevier Applied Science Publishers, 1984. p. 1-34.

6 GREEN, M. L.; FOSTER, P. M. D. Comparasion of the rates of proteolysis during ripening of Cheddar cheeses made with calf rennet and swine pepsin as coagulants. J. Dairy Res., v. 41, p. 269-282, 1974.

7 GREEN, M. L.; MANNING, D. J. Development of texture and flavor in cheese and other fermented products. J. Dairy Res., v. 49, p. 737, 1982.

8 KOSIKOWSKI, F. V. Cheese and fermented milk foods. $2^{\text {nd }}$. ed. New York: Brooktondale, 1982. 711 p.

9 LAEMMLI, U. K. Cleavage of structural proteins during the assembly of the head of bacteriophage T.4. Nature, v. 227, p. 680, 1970.

10 LANARA. Laboratório Nacional de Referência Animal. Métodos analíticos oficiais para controle de produtos de origem animal e seus ingredientes. II. Métodos físico-químicos. Brasília, 1981.

11 LAW, B.A. Proteolysis in relation to normal and accelerated chesse ripening. In: FOX, P. F. (Ed.). Cheese: chemistry, physics and microbilogy, general aspects. London: Elsevier Applied Science, 1987. v. 1.

12 LIMA, M. H. P.; TELLES, F. J. S.; MACEDO, B. A. et al. Elaboração de queijo de coalho a partir de leite pasteurizado e inoculado com Streptococcus thermophillus e Lactobacillus bulgaricus: aspectos bioquímicos e sensorial. Boletim CEPPA, v. 16, n. 1, p. 37-44, jan./jun. 1998.

13 LOWRY, O. H.; ROSEBROUGH, N. J.; FARR, A. L. et al. Protein measurement with the Folin Phenol reagent. Journal of Biological Chemistry, v. 193, p. 265-275, 1951.

14 MORAES, M. A. C. Métodos para avaliação sensorial dos alimentos. 6. ed. Campinas: UNICAMP, 1988. $101 \mathrm{p}$. 
15 NATH, K. R.; LEDFORD, R. A. Growth response of Lactobacillus casei var. casei to proteolysis products in cheese during ripening. $\mathbf{J}$. Dairy Sci., v. 56, p. 110, 1973.

16 REITER, B.; SOROKIN, Y.; PICKERING, A. et al. Hydrolysis of fat and protein in small Cheeses made under asseptic conditions. J. Dairy Res., v. 36, p. 65-76, 1969.

17 SAMPLES, D. R.; RITCHER, R. L.; DILL, C. W. Measuring proteolysis in Cheddar cheese slurries: comparision of hull and trinitrobenzene sulfonic acid procedures. J. Dairy Sci., v. 67, p. 6063, 1984.

18 SCHORMULLER, J. The chemistry and biochemistry of cheese ripening. Adv. Food Res., v. 16, p. 231, 1968.

19 SIQUEIRA, J. F. M.; COELHO, D. T.; CHAVES, J. B. P. et al. Efeito da variação do teor de gordura do leite no rendimento do queijo Minas padronizado. R. Inst. Latic. Cândido Tostes, Juiz de Fora, v. 41, n. 245, p. 21-26, 1986.

20 SMITH, L. F. Avaliações sensoriais de queijo. R. Inst. Latic. Cândido Tostes, Juiz de Fora, v. 40, n. 239, p. 106-118, 1985.

21 VAKALERIS, D. G.; PRICE, W. V. A rapid spectrophotometric method for measuring cheese ripening. J. Dairy Sci., v. 42, p. 264276, 1959. 